\title{
Joint use of data and modeling in coastal wave transformation
}

\author{
Conceição Juana Fortes • Óscar Ferreira • \\ Paulo A. Silva • Theo Moura • Rui Capitão • \\ Luís Amante • Michalis Vousdoukas • Maria Bezerra
}

Received: 19 May 2010 /Revised: 31 December 2010 / Accepted: 26 January 2011 / Published online: 20 March 2012

(C) The Author(s) 2012. This article is published with open access at Springerlink.com

\begin{abstract}
In the framework of a research project entitled "BRISA-BReaking waves and Induced SAnd transport", a methodology was devised to characterize the waves joining together in-situ measurements and numerical wave propagation models. With this goal in mind, a number of in-situ measurements were made, for selected positions in front of Praia de Faro (South Portugal), during four days (25th to 28th March, 2009) by using different types of equipments (e.g., resistive wave gauges, pressure sensors, currentmeters
\end{abstract}

\author{
C. J. Fortes $(\bowtie) \cdot$ T. Moura $\cdot$ R. Capitão \\ Laboratório Nacional de Engenharia Civil, \\ Av. do Brasil 101, \\ 1700-066 Lisboa, Portugal \\ e-mail: jfortes@lnec.pt \\ T. Moura \\ e-mail: tmoura@lnec.pt \\ R. Capitão \\ e-mail: rcapitao@lnec.pt
}

P. A. Silva $\cdot$ L. Amante

CESAM \& Departamento de Física da Universidade de Aveiro, Campus Universitário de Santiago,

3810-193 Aveiro, Portugal

e-mail: psilva@ua.pt

L. Amante

e-mail: luis.amante@ua.pt

Ó. Ferreira $\cdot$ M. Vousdoukas $\cdot$ M. Bezerra

CIMA, Universidade do Algarve,

Edifício 7, Campus de Gambelas,

8005-139 Faro, Portugal

e-mail: oferreir@ualg.pt

M. Vousdoukas

e-mail: vousdoukas@fzk-nth.de

M. Bezerra

email: mbezerra@ualg.pt and a new prototype pore pressure sensor using optical fibre). Wave records were obtained simultaneously offshore (at a water depth of $11.7 \mathrm{~m}$ below mean sea level, MSL) and at the surf and swash zones. The data processing and analysis were made by applying classical time domain techniques. Numerical simulations of the wave propagation between offshore and inshore for the measurement period were performed with two numerical models, a 1D model based on linear theory and a nonlinear Boussinesq-type model, COULWAVE, both forced by the measured offshore wave conditions of 27th March 2009. Comparisons between numerical results and field data for the pressure sensors placed in the surf and swash zones were made and discussed. This approach enables to evaluate the performance of those models to simulate those specific conditions, but also to validate the models by gaining confidence on their use in other conditions.

Keywords Waves $\cdot$ Surf and swash area $\cdot$ Field measurements $\cdot$ Numerical modelling $\cdot$ COULWAVE

\section{Introduction}

Wave breaking is an important phenomenon in the nearshore region, linked with a number of other important nearshore processes, such as set-up/down, longshore currents, nearshore circulation amongst others. These phenomena control nearshore hydrodynamics and sediment transport, which affect coastal morphodynamics and coastal structures stability. Wave breaking, the associated sediment transport, and morphological changes can be analyzed for specific conditions by using field measurements. Field measurements are, however, limited in time. The use of validated numerical models can be of great help to define wave 
transformation for all wave conditions, improving the subsequent determination of sediment transport and morphological changes.

The main goal of this paper is to compare numerical model results against field data in order to validate the models and gain sensitivity to differences between measurements and predictions. For that purpose, the paper describes a field campaign for wave, currents, sediment transport and morphological measurements on low energy conditions, and presents the results for the basic analysis of the hydrodynamic data. Two numerical models were applied to the observed conditions (a 1D model based on linear theory, 1DL, and a nonlinear Boussinesq type model, COULWAVE, Lynett and Liu 2004) and a comparison between field data and model results is discussed. These efforts aim to assess the performance of the used models on the studied area for the observed low energy conditions and, in a general way, to contribute to reach the optimal approach for model applications in larger temporal and spatial scales, required from an operational/management perspective.

\section{Study area}

The study area is Praia de Faro (Ancão Peninsula) located in the Ria Formosa barrier island system, southern Portugal (Fig. 1). The length of Ancão Peninsula is variable (from 8.5 to $12.8 \mathrm{~km}$ between 1947 and 2001) (Matias et al. 2008) due to changes in the Ancão Inlet position, which migrates eastward at rates of 40 to $100 \mathrm{~m} /$ year (Vila-Concejo et al. 2006). The peninsula is narrow, with a width ranging from 50 to $250 \mathrm{~m}$, and the dunes can be single-crested and reach $5.5 \mathrm{~m}$ above mean sea level (MSL) (Matias et al. 2008).

The study area has a mean tidal range of $2.8 \mathrm{~m}$ during spring tides and $1.3 \mathrm{~m}$ during neap tides with a maximum tidal range of $3.5 \mathrm{~m}$ (Instituto Hidrográfico 1998). The offshore wave climate is dominated by W-SW waves $(71 \%$ of occurrences) (Costa et al. 2001). Southeast short period waves generated by regional winds are also frequent (about 23\%) (Costa et al. 2001). Wave energy is moderate with a significant annual average offshore height of $1.0 \mathrm{~m}$ and an average peak period of $8.2 \mathrm{~s}$ (Costa et al. 2001). According to Costa et al. (2001) significant wave height lower than $1 \mathrm{~m}$ is registered during $68 \%$ of the year. A storm, in this part of the Portuguese coast, is defined as an event with significant offshore wave height higher than $3 \mathrm{~m}$ (Pessanha and Pires 1981; Melo 1989; Costa 1994). Southwest storm waves have a significant average height higher than Southeast storms (Costa 1994). Southwest storms account for 64\% of occurrence and southeasterly storms for $32 \%$ (Costa et al. 2001). A $5 \mathrm{~m} \mathrm{SE}$ storm has an estimated return period of 50 years, whereas a $5.7 \mathrm{~m} \mathrm{SW}$ storm is expected every 5 years (Pires 1998). The Ancão Peninsula is directly exposed to the W-SW waves, and relatively protected from Southeast waves.

\section{In-situ measurements}

Within the scope of the BRISA research project, a field measurement campaign took place during March, 25th28th, 2009, at Praia de Faro, in which a wide array of instruments was used. This section summarizes the characteristics of the instruments and of the measurements made.

\section{Waves and currents}

For waves and currents measurements, an array of equipments was deployed both at nearshore and at the beachface of Praia de Faro. An ADP (Acoustic Doppler Profiler) and an Infinity PT (Pressure Transducer) were placed at the nearshore at $2.5 \mathrm{~m}$ and $11.7 \mathrm{~m}$ below mean sea level (MSL), respectively (Fig. 1). The remaining equipment was installed along two cross-shore transects (P3 and P4) at Praia de Faro, near the restaurant "O Paquete" (Fig. 2). The equipment deployed at these profiles consisted in:

- Valeport Midas-6 PTs (Pressure Transducers) array (PTV);

- ECM (Electromagnetic Current Meters) (ECMV and ECML);

- Acoustic Doppler Velocimeters (ADVA and ADVL)

- Single PT (Pressure Transducer) (PTA)

- $\quad$ Array of 3 PTs (PTL)

All instruments were geo-referenced after installation on low tide using a RTK-GPS. Furthermore, all equipments were synchronized with Observatório Astronómico de Lisboa time. The Infinity PT started to record at 25/03/09, 00:00 am and stopped at 28/03/09 at 24:00 pm. The other instruments started to record at 26/03/09, 07:00 am, and data acquisition was carried out until 28/03/09 at 10:00 pm. For the purposes of this paper only data from 27th March were used.

The sampling frequencies and elevation of the sensors are given in Table 1.

Topographic and bathymetric surveys

To monitor morphological changes 6 topographic surveys were performed in low tide, using a RTK-GPS measuring 11 cross-shore and 8 longshore profiles. One bathymetric survey was made to obtain a detailed bathymetric grid for modeling applications and detailed topographic analysis. The survey included 4 cross-shore profiles from the beach face until $12 \mathrm{~m}$ depth MSL (closure depth complemented by 16 longshore lines with varying spacing. The width of the 


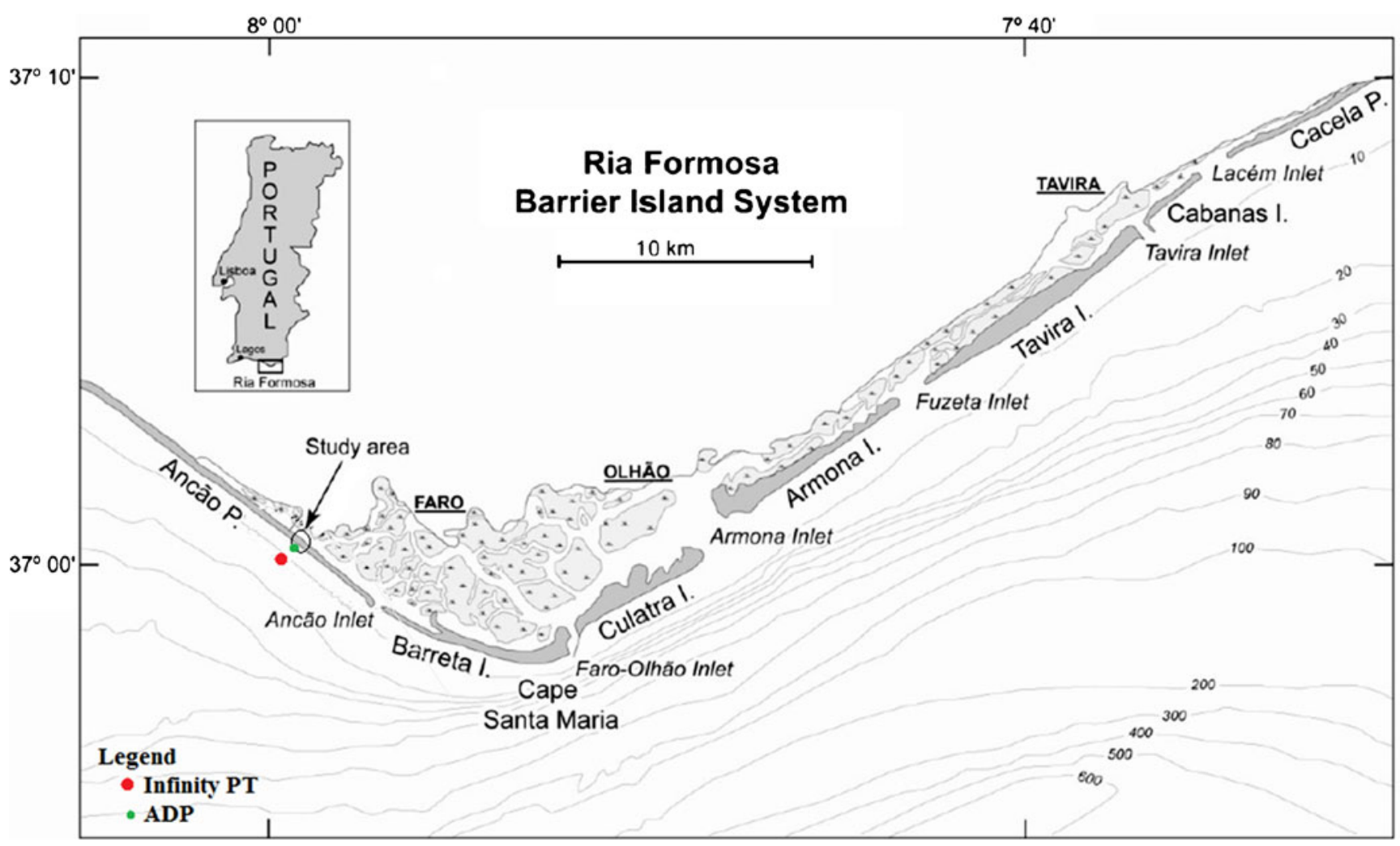

Fig. 1 Location of the study area, Infinity PT and ADP (base map adapted from Matias et al. 2009)

surveyed bathymetry was of about $100 \mathrm{~m}$. Since the bottom is relatively regular, this bathymetry can be used for propagation of shore normal waves without causing numerical modeling problems. Combining the bathymetric and the topographic grid it was possible to obtain a detailed grid from $12 \mathrm{~m}$ below MSL to $5 \mathrm{~m}$ above MSL (Fig. 3).
Fig. 2 Location of the main deployed equipment (blue, red and yellow colors correspond to equipment from the Aveiro University, the Algarve University and the National Laboratory of Civil

Engineering, respectively). PT -Pressure transducer; ADVAcoustic Doppler Velocimeter; ECM-Electromagnetic Currentmeter. Base Map: Ortophotomap 2009

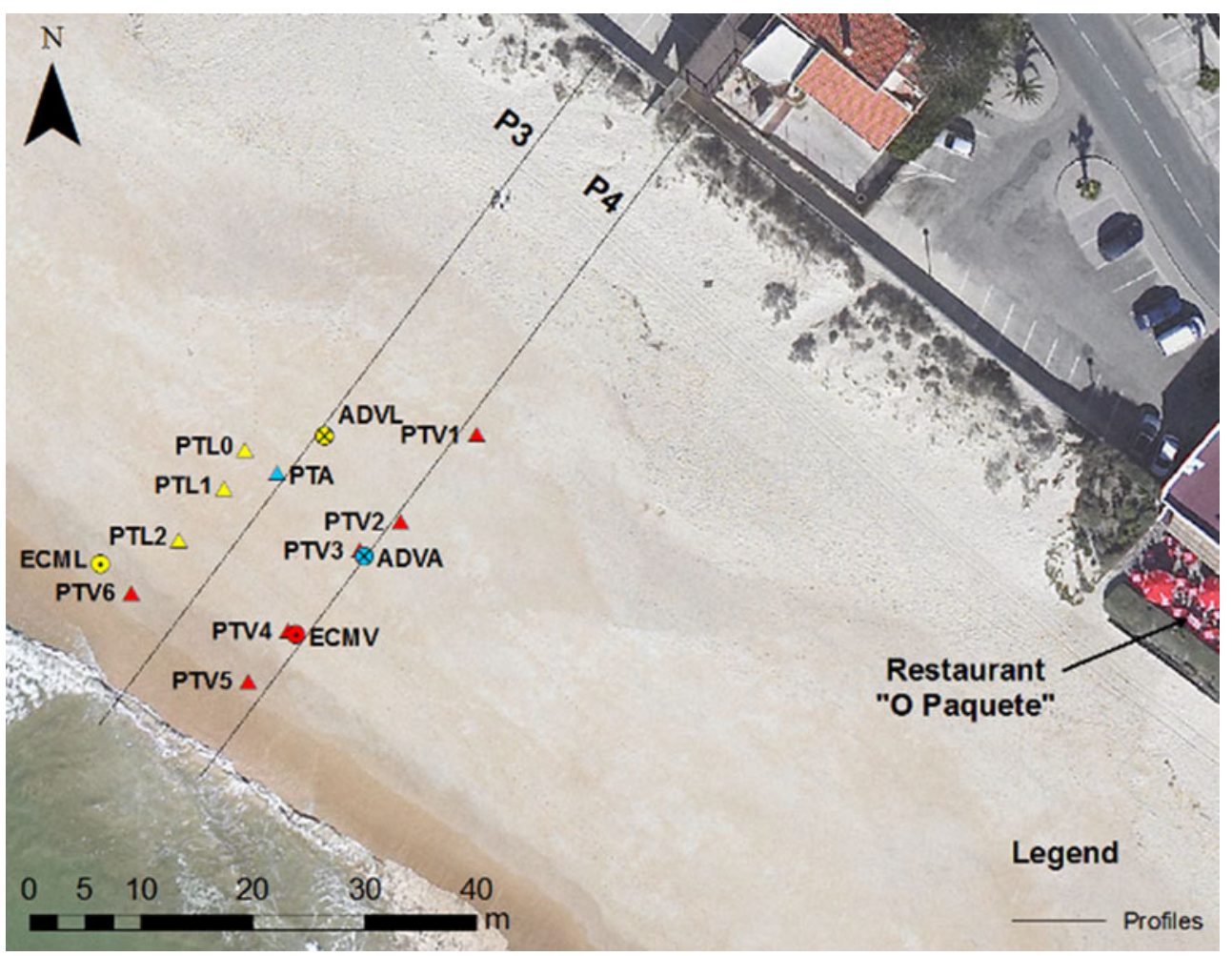


Table 1 Elevation (referred to MSL) and sampling frequencies of the deployed equipment

\begin{tabular}{llcc}
\hline Profile id & Equipment & Elevation (m) & Frequency (Hz) \\
\hline P4 & PTV1 & 3.41 & 5 \\
P4 & PTV2 & 2.02 & 5 \\
P4 & PTV3 & 1.56 & 5 \\
P4 & PTV4 & 0.18 & 5 \\
P4 & PTV5 & -0.54 & 5 \\
P3 & PTV6 & -0.80 & 5 \\
P4 & ECMV & 0.27 & 4 \\
P4 & ADP & -2.50 & Waves: 2 Hz, Current \\
& & & profiles: mean every \\
& & & 1 min \\
Offshore & Infinity PT & -11.70 & 4 \\
P3 & PTL0 & 1.71 & 25 \\
P3 & PTL1 & 1.12 & 2 \\
P3 & PTL2 & 0.20 & 25 \\
P3 & ECML & -0.72 & 5 \\
P3 & ADVL & 2.21 & 1 \\
P3 & PTA & 1.42 & 20 \\
P4 & ADVA & 1.69 & \\
\hline
\end{tabular}

A sub-bottom pressure sensor system based on optical fiber sensors developed within the BRISA project was deployed in the surf and swash zone in the cross-shore transect P3 for monitoring the dynamic variations of the sea bed level. The sensor is based on a fiber Bragg grating embedded in a polyurethane resin block. The resin act as a pressure transducer. The increase of the pressure on the top face of the sensor, due to the change of sediments layer height, results in a change of the FBG Bragg wavelength. The sensor response reveals the capacity to discriminate sea bed level changes down to $2.5 \mathrm{~cm}$, under field survey conditions. (Ferreira et al. 2009).

\section{Sediment sampling}

Sediment samples were obtained along the two defined topographic profiles (P3 and P4, Fig. 2), at every low tide. At the first sampling tide (26th March) the cross-shore spacing between samples was $10 \mathrm{~m}$, from the low tide shoreline until the dune. For the other tides, 3 samples were obtained at each profile. Also, complementary samples were taken near the ADVA and ECMV location.

\section{Data processing}

To get insight into the hydrodynamics of the study area during the campaign, this section presents the free surface elevation data obtained both offshore and inshore for selected instruments. Measurements obtained during the field work with the Infinity PT, at a water depth of $11.7 \mathrm{~m}$ below MSL and with two types of pressure transducers at the
Fig. 3 Obtained topobathymetric digital terrain model (27/03/09). Elevation is referred to ZH (Zero Hidrográfico), $2 \mathrm{~m}$ below MSL

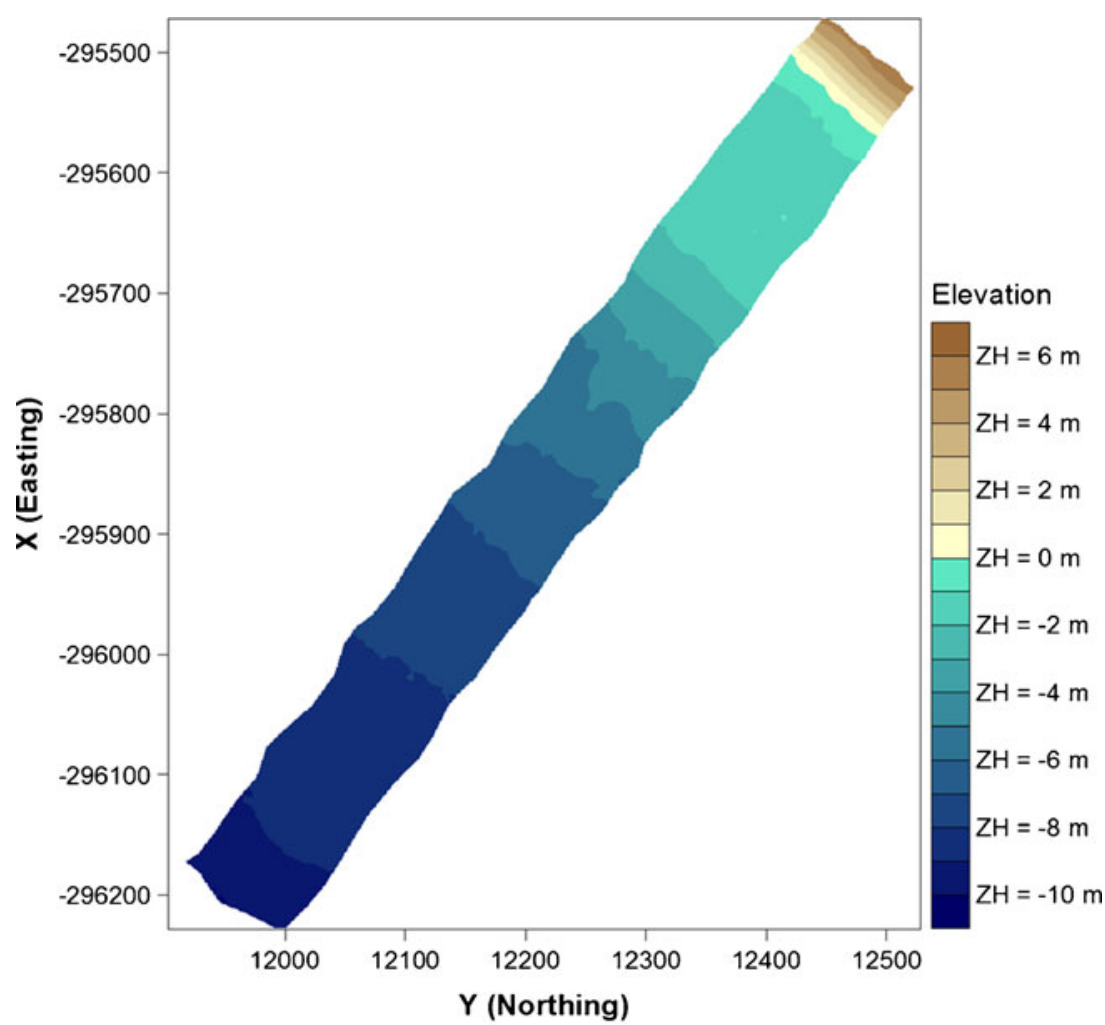


shoreface and swash (a vented pressure transducer "Honeywell", PTL2, and a non-vented pressure transducer, "LevelTROLL500", with data-logger, PTL1) are presented and analysed. The positions of these equipments are shown in Fig. 2.

These data, although representing just a part of the hydrodynamic data that was collected during the campaign, were the ones used as boundary conditions (offshore data) of the numerical models as well as used for comparisons to evaluate the performance of those models in shallow areas (inshore data).

\section{Infinity PT data}

Using the Infinity PT raw data and a Matlab routine, the following wave parameters were determined: significant wave height (HS), mean wave height (HM) (Fig. 4), peak period (TP), mean period (TM) and significant period (TS) (Fig. 5).

Observed HS was between 0.2 and $0.6 \mathrm{~m}$, corresponding to low energy waves, arriving both from SE (until the 28th of March) and from SW (during the 28th of March). TP shows important and rapid changes for the study period while TS shows a more regular pattern with higher values for SW conditions.

PTL1 (LevelTROLL) and PTL2 (Honeywell) data

In the present work only the data concerning the two pressure transducers "LevelTROLL" (PTL1) and "Honeywell"
(PTL2) are considered. The analysis of the records involved the following set of procedures:

- Removal of the tidal component using high-pass digital filters;

- Separation of the total measurement record of PTL1 into 30-min-duration records, each representing a stationary sea state, ready for subsequent time and spectral analysis. This operation was not necessary for the "Honeywell" pressure sensor (PTL2) because its records had already that duration;

- Time analysis of those records with computer programs REGISTOS (Fortes and Capitão 2009) and ANOIAGI (Carvalho 1981). For each record, parameters HS, TS and TM were obtained.

Figures 6 and 7 show the obtained values of HS, TS and TM, computed using classical time analysis (direct method), for PTL1 and PTL2.

The above results led to the identification of the main characteristics of the sea states present at the Praia de Faro beach during the fieldwork which are summarized in the following:

- The wave conditions correspond to low energy conditions;

- There are no significant differences between the wave characteristics obtained in both pressure sensors: PTL2 (Honeywell) and PTL1 (LevelTROLL). This was expected due to the small distance between them. Also, although the sensors are of different nature and

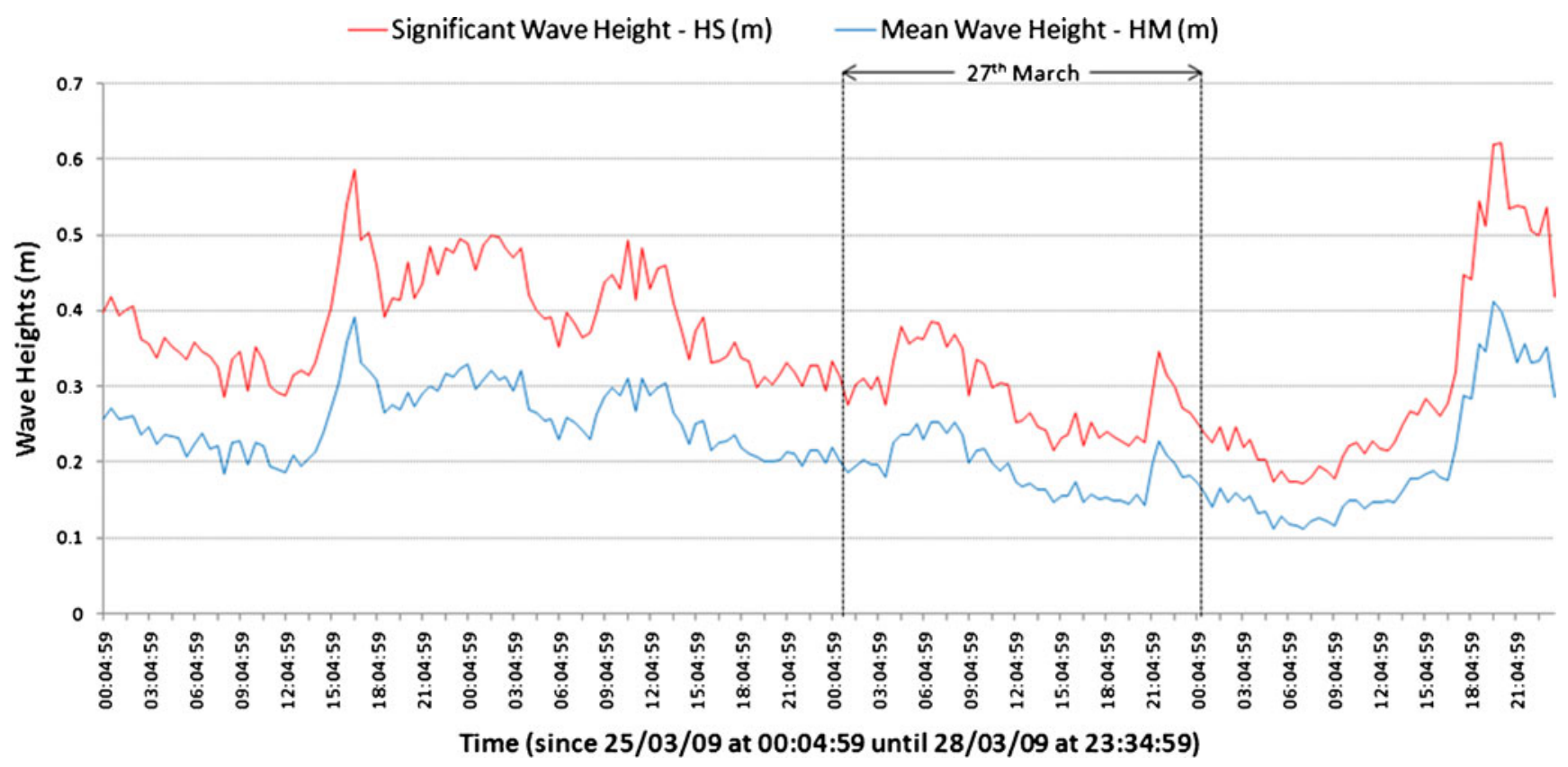

Fig. 4 Graphical representation of significant wave height-HS (m) and mean wave height- $\mathrm{HM}(\mathrm{m})$ during the campaign obtained from the Infinity PT data (11.7 m below MSL) 


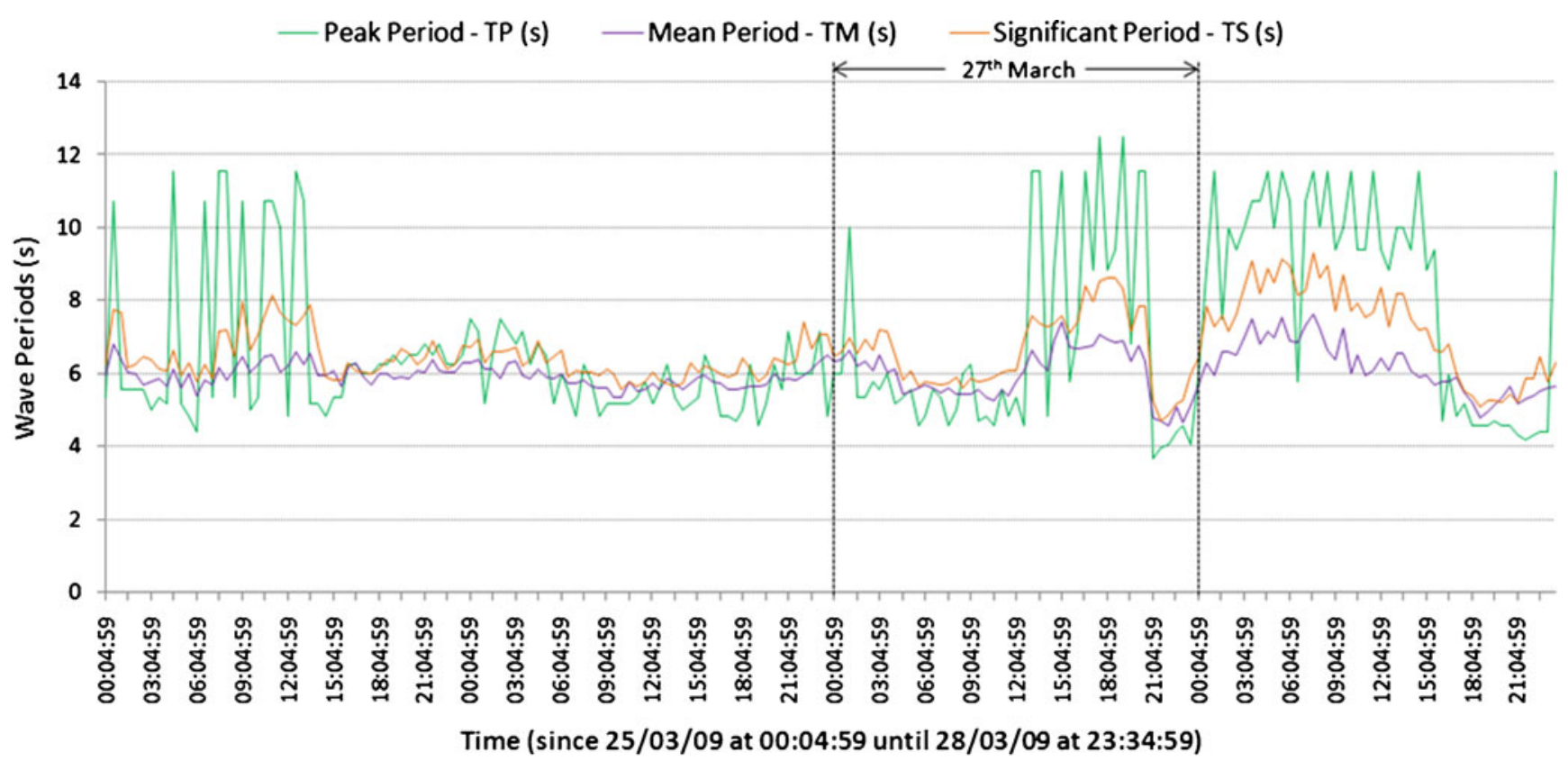

Fig. 5 Graphical representation of peak period-TP (s), mean period-TM (s) and significant period—TS (s) during the campaign obtained from the Infinity PT data (11.7 $\mathrm{m}$ below MSL)

capabilities, output values are expected to be very similar for this type of measurements. In particular:

- HS varied between $0.3 \mathrm{~m}$ and $0.5 \mathrm{~m}$ (PTL1) and $0.2 \mathrm{~m}$ and $0.5 \mathrm{~m}$ (PTL2).

a

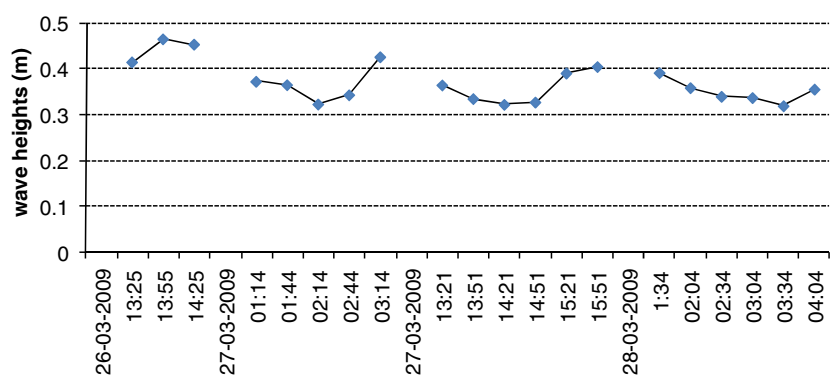

b

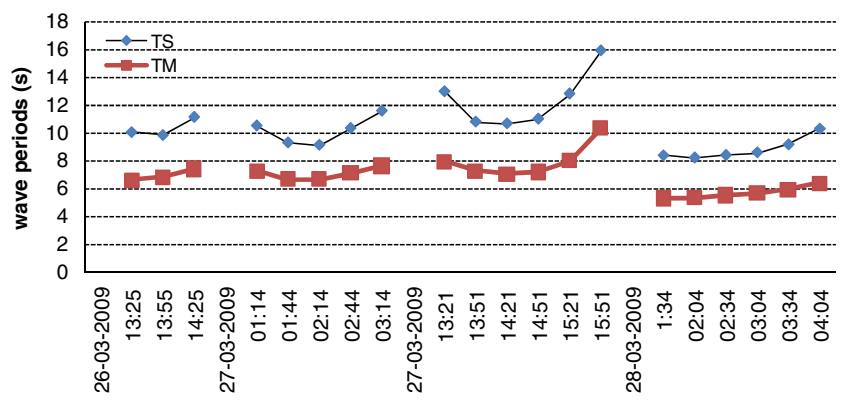

Fig. 6 Values of (a) significant wave height, HS, and (b) significant wave period, TS, and mean wave period, TM, for PTL1 (LevelTROLL)
- TS varied between $8 \mathrm{~s}$ and $16 \mathrm{~s}$ (PTL1) and $5 \mathrm{~s}$ and $10 \mathrm{~s}$ (PTL2);

- TM varied between $5 \mathrm{~s}$ and $10 \mathrm{~s}$ (PTL1) and $3 \mathrm{~s}$ and 7 s (PTL2).

It should be noted that there are no significant differences between the offshore and inshore wave height values, both offshore and inshore results show a general tendency to a decrease of HS between 26th 15:00 and 28th March, 2:00. In general, the inshore values at the pressure transducers are slightly higher than offshore due to shoaling.

TM values are similar for both offshore and inshore conditions. The same does not happen with the TS values, which increase from offshore to inshore, especially for 26th 15:00 and 28th March, 12:00. This may be related with the position of the pressure transducers. Some waves might break before reaching the PTs, others interact with the backwash, not reaching the pressure transducer. This is more evident for PTL1 than for PTL2.

\section{Numerical modelling}

Two numerical models (a 1D linear model, 1DL, and the COULWAVE) were used to simulate the wave propagation for the campaign's conditions (27th March 2009) and the results compared with the field data. While the $1 \mathrm{DL}$ is a very simple linear refraction model associated with a simple wave breaking condition, the COULWAVE is a nonlinear Boussinesq type model particularly adapted to wave 
Fig. 7 Values of (a) significant wave height, HS, and (b) significant wave period, TS, and mean period, TM, for PTL2 (Honeywell) a

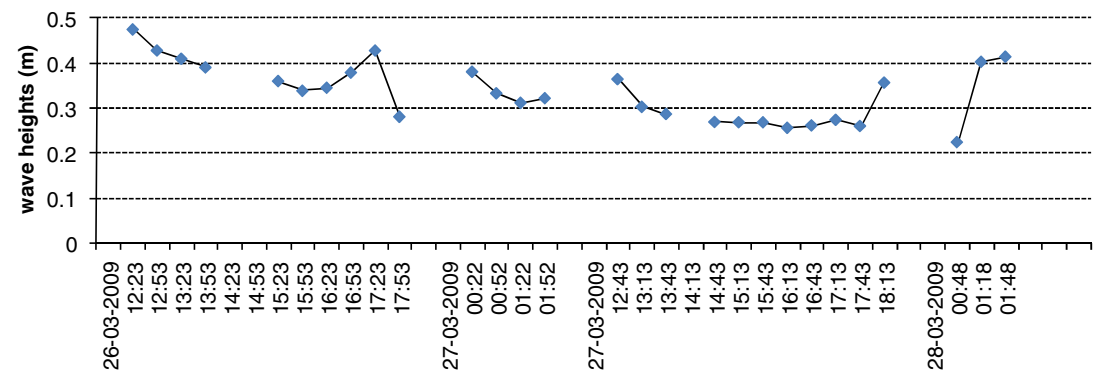

b

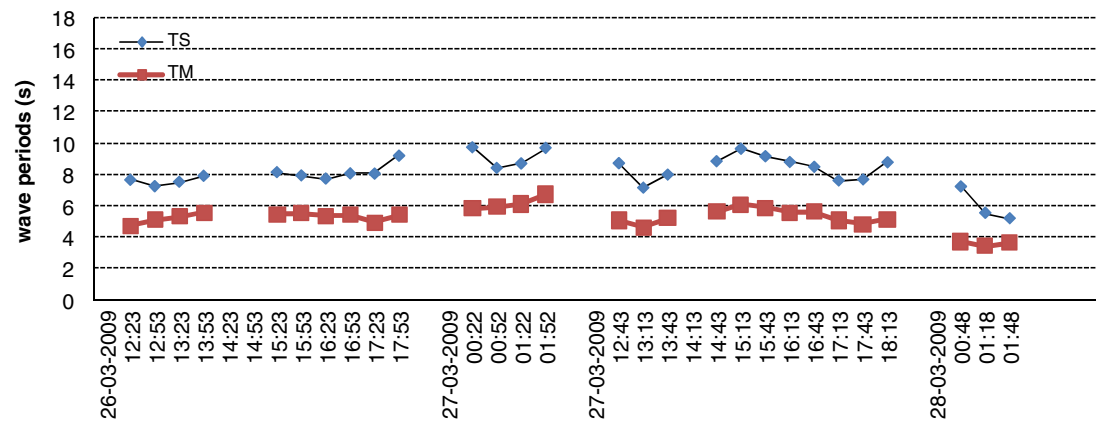

characterization in the nearshore area since it takes into account the main phenomena present in the wave propagation (for instance, wave refraction, diffraction, reflection, wave breaking, bottom friction and nonlinear phenomena). COULWAVE is a quite demanding model in terms of CPU computational time and memory storage and most of the parameters related with wave breaking, wave friction, etc., must be calibrated.

The above models were used to propagate the offshore wave conditions observed at the Infinity PT $(-11.7 \mathrm{~m}$ water depth) up to the surf and swash zones. Two types of simulations were performed:

- Use of a regular wave as a boundary condition for the 1DL and COULWAVE models, given by the offshore wave field parameters (significant wave heights and wave periods) measured along the 27th March. The corresponding numerical solutions and measured values of significant wave heights are compared at PTL2 position;

- Use of the offshore (Infinity PT) 10 min-duration free surface elevation measured at 2:30 am of 27th March as boundary conditions for the COULWAVE model and comparison with both the corresponding numerical solution and the measured free surface elevation at the PTL1 position. Note that the use of a short time period duration (too short to be considered as stationary period) is related to the fact that each burst at the infinity PT had only 10 minutes.

While the first simulation permits to evaluate the main differences obtained between considering a simple model and a more complex one, the second simulation is more close to the field situation since the time series of free surface elevation is the offshore condition.

The next sections present a brief description of the numerical models, their computational conditions and the comparison between numerical and field data for the two types of offshore conditions.

Numerical models description

The 1D linear model (1DL) for wave propagation is based on the linear theory and under the assumption of straight and parallel bathymetric contours and conservation of wave energy (Dean and Dalrymple 1991). Under these conditions the wave's height, $H$, at a water depth $h$ is computed from the wave's height further offshore, $H_{0}$ :

$H=H_{0} K_{s} K_{r}$

$K_{s}=\sqrt{C_{g 0} / C_{g}} ; K_{r}=\sqrt{\cos \theta_{0} / \cos \theta}$

$K_{s}$ and $K_{r}$ represent, respectively the shoaling coefficient and the refraction coefficient, $C_{g}$ the group velocity and $\theta$ the local wave direction angle which is evaluated from Snell's law. The wave breaking criteria considered in this formulation assumes that the wave height does not exceed a threshold value of $q$ of the water depth and breaking is attained if this condition is met. A second criterion considers the beach slope (e.g., Dean and Dalrymple 1991). 
COULWAVE (Lynett and Liu 2004) is a nonlinear wave propagation model based upon a multi layer approach for the integration of the primitive equations of motion (continuity and momentum equations). This approach leads to a set of model equations without the high-order spatial derivatives associated with high-order polynomial approximations.

The optimized model equations show good linear wave characteristics up to a $k h$ ( $k$ is the wave number) of 8 , while the second-order nonlinear behavior is well-captured to $\mathrm{kh} \sim 6$. This is a greater than two-fold extension to higher kh over existing $\mathrm{O}(1)$ Boussinesq-type. To enable the Boussinesq model to simulate surf zone hydrodynamics, the energy dissipation due to wave breaking is treated by introducing an eddy viscosity term into the momentum equations, with the viscosity strongly localized on the front face of the breaking waves. This extra momentum term is only active during the wave breaking event which is controlled by an external wave breaking index- the triggering wave breaking mechanism. The triggering criterion is based in the vertical speed parameter presented by Kennedy et al. (2000), which depends on several parameters (initiation, duration, termination of wave breaking) and needs to be calibrated for each study. Wave run-up on the beach is simulated using a permeable seabed technique (slot technique). Both wave breaking and run-up schemes are described in Kennedy et al. (2000).

Model conditions

\section{DL model}

The 1D computational domain and the corresponding beach profile, obtained from the bathymetric and topographic measurements performed during the campaign, are presented in Fig. 8. The model computes the wave's height along the beach profile given the corresponding offshore boundary conditions.

The calculations were performed for regular waves which characteristics are the offshore wave conditions observed at the Infinity PT placed at $11.7 \mathrm{~m}$ below MSL during 27th March, 2009. Notice that offshore numerical wave conditions (in terms of significant wave heights and wave periods) were determined based upon a time analysis of the time series of the free surface elevation, considering periods of 10 minutes each 30 minutes. The reason for considering only 10 minutes is due to the fact that the Infinity PT data was obtained with bursts of 10 minutes with a 30 minutes step. In the present applications the incident wave angle was considered equal to $0^{\circ}$ as in COULWAVE model setup.

As an example, Fig. 9 shows the numerical solution obtained for an incident wave of $\mathrm{H}=0.27 \mathrm{~m}$ and $\mathrm{T}=9 \mathrm{~s}$. The lower panel also illustrates the dependence of the numerical solution on the wave breaking criteria considered. The range values for the threshold breaking limit, $q$, considered are representative of the values found in the literature (see for example, Dean and Dalrymple (1991) and Damgaard et al. (2001)). Wave height increases as the distance to the shore decreases. The value of $q$ determines the maximum height achieved and the breaking position.

\section{COULWAVE model}

The 2D computation domain used by the COULWAVE model is presented in Fig. 8b. It is $700 \mathrm{~m}$ long and $120 \mathrm{~m}$ width. Note that point (0.0) is real coordinates (12047.53, 296178.78). The grid bathymetry has a constant spacing of $\Delta \mathrm{x}=\Delta \mathrm{y}=2 \mathrm{~m}$. Notice that the $\Delta \mathrm{x}$ and $\Delta \mathrm{y}$ of the computational grid of COULWAVE is different for every simulation.
Fig. 8 (a) Domain and bathymetry of the computational domain for 1DL and COULWAVE simulations (b) Position of the pressure transducers (PTL1 and PTL2) (red dots). Elevation is referred to $\mathrm{ZH}, 2 \mathrm{~m}$ below MSL a

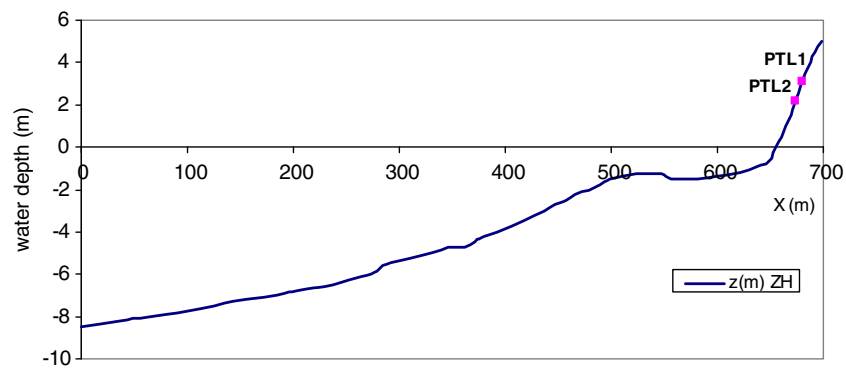

b

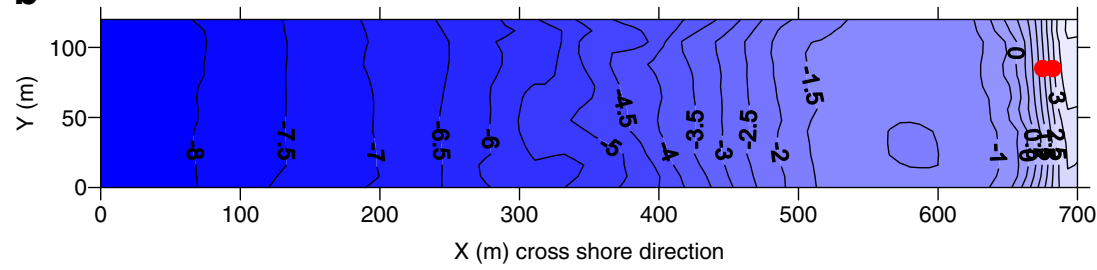


Fig. 9 1DL numerical solution obtained for an incident wave of $\mathrm{H}=0.27 \mathrm{~m}$ and wave period of $\mathrm{T}=9$ s.: (a) $q=0.7$; (b) $q=0.4,0.7$ and 0.78 (also depending on the beach slope) a

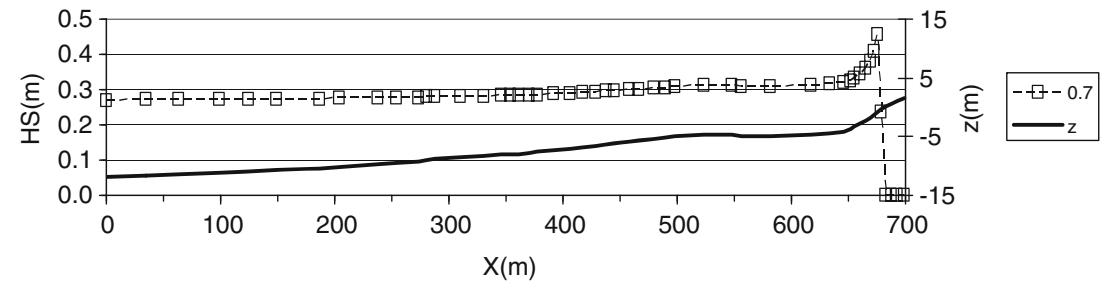

b

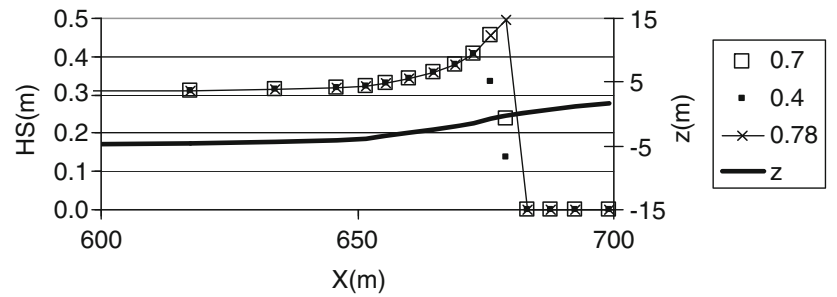

The spatial and the temporal discretization depend on the Courant number and also on the wave period set on the boundary. In fact, the COULWAVE model generates a finite difference grid also based upon the minimum number of points per wavelength given by the user, which in this case were 40 . The Courant number was equal to 0.4 .

Two absorbing boundaries were considered at the beginning and at the end of the domain with a length of 1.25 wave length. The source function for the wave generation is located normal to $\mathrm{x}$ axis at $\mathrm{y}=0.0 \mathrm{~m}$. The total simulation time was $1000 \mathrm{~s}$. All simulations were performed considering one-layer only, the fully nonlinear equations, wave breaking and wave friction. It was considered a friction coefficient equal to $1.0 \times 10^{-2}$. For the remaining model parameters it was assumed, as a first approach, the values suggested in the COULWAVE model user's manual (Lynett and Liu 2004).

As referred, regular waves with offshore wave conditions (HS, TS) observed at the Infinity PT during 27th March, 2009 were imposed on the boundary of the numerical model. In these calculations it was considered that the wave direction is perpendicular to the computation domain. This represents an important simplification, not possible to overcome at the moment since with the Infinity PT it is not possible to get the offshore wave directions. This simplification can contribute to differences on the results of the numerical model.

As an example, Fig. 10 shows the wave heights along one section of the domain $\mathrm{y}=85 \mathrm{~m}$, for an incident wave of $\mathrm{H}=0.27 \mathrm{~m}$ and $\mathrm{T}=9 \mathrm{~s}$.

From the analysis of Fig. 10, a general tendency can be observed: the wave height increases, due to shoaling, as it approaches the shoreline, especially after $\mathrm{x}=500 \mathrm{~m}$. Close to the shoreface $(\mathrm{x}=670 \mathrm{~m})$ wave breaking is observed.

It is also clear that wave reflection occur due to the steepness of the bottom profile near the shoreface. Moreover, the generation of a monochromatic wave at the entrance boundary is probably responsible to produce this regular shape of reflective waves. This is evident in the numerical model results and affects all the wave heights along the profile.

In relation to the $1 \mathrm{DL}$ model, the behaviour of both models is similar, i.e., both show an increase of the wave height due to shoaling followed by the wave breaking that occurs around $x=650 \mathrm{~m}$. The main differences are related with wave heights near breaking (COULWAVE present a higher value than 1DL value) and with wave reflection that is not considered at the 1DL model and do influence the nonlinear model results.

\section{Comparison between model's results and observed wave data}

Regular waves Figures 11 and 12 show the numerical significant wave heights (1DL and COULWAVE) and corresponding

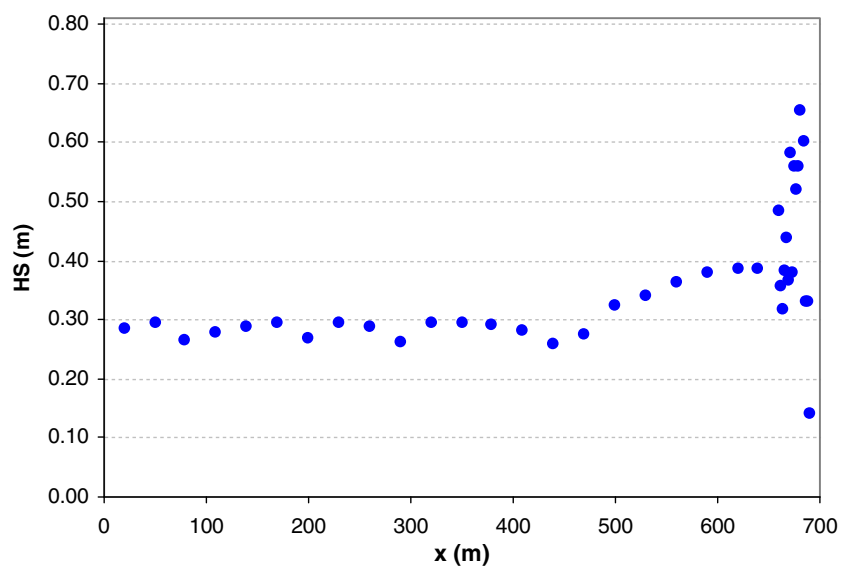

Fig. 10 Significant wave heights along the $y=85 \mathrm{~m} . \mathrm{H}=0.27 \mathrm{mT}=9 \mathrm{~s}$, 27th March, 04:10 pm, Sea level=3.1 $\mathrm{m}$ above MSL 


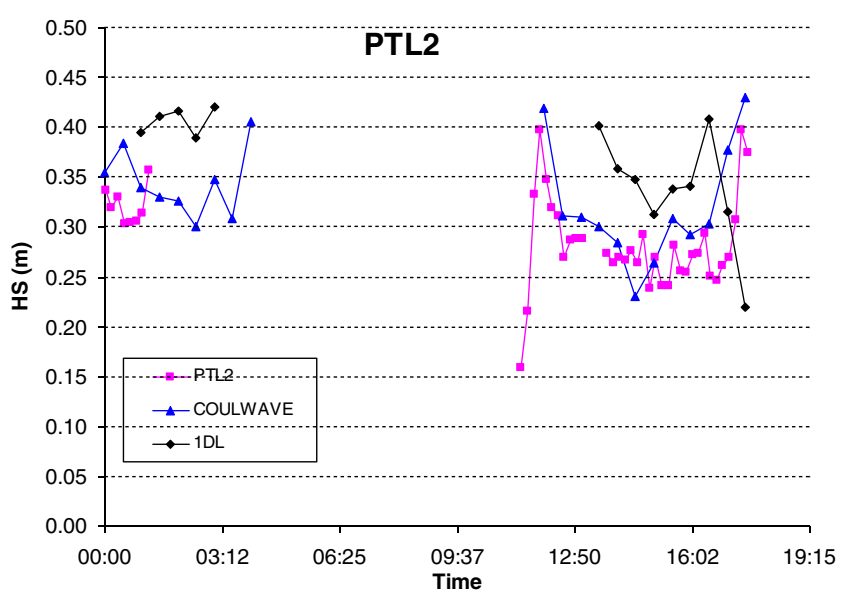

Fig. 11 27th March. HS values at PTL2 position, obtained with the Honewell (PTL2) data and with both COULWAVE and 1DL models

measurements at the pressure sensors PTL2 and PTL1, respectively.

Table 2 presents the average error (BIAS), the route mean square error (RMSE) and the Wilmott index (IC) values obtain between numerical and measured data, for PLT2 and PTL1 positions, considering:

$$
\begin{aligned}
\text { RMSE } & =\sqrt{\frac{\sum_{i=1}^{n}\left(y_{i}-x_{i}\right)^{2}}{n}} \text { bias }=\frac{\sum_{i=1}^{n}\left(y_{i}-x_{i}\right)}{n} i c \\
& =1-\frac{\sum_{i=1}^{n}\left|y_{i}-x_{i}\right|^{2}}{\sum_{i=1}^{n}\left(\left|y_{i}-x\right|+\left|x_{i}-x\right|\right)^{2}}
\end{aligned}
$$

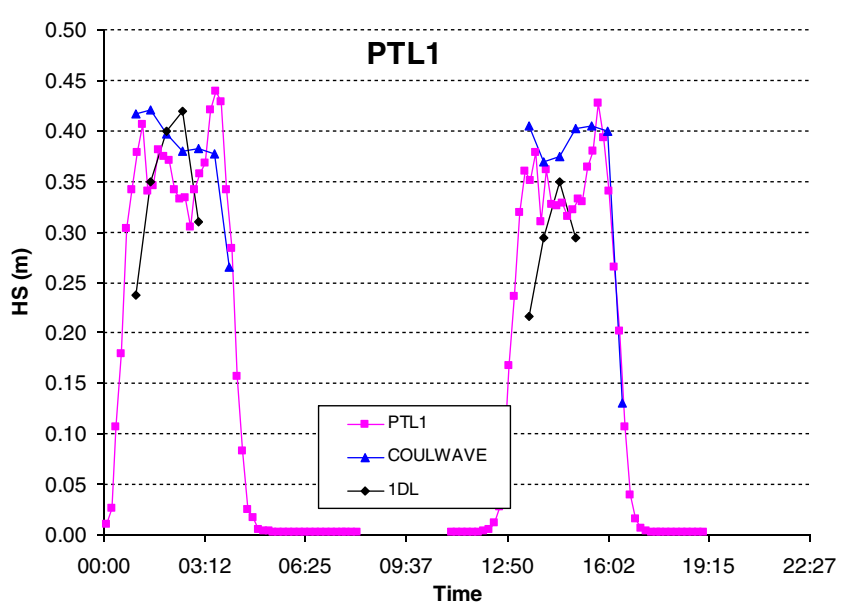

Fig. 12 27th March. HS values at PTL1 position, obtained with the LevelTROLL (PTL1) data and with both COULWAVE and 1DL models
Table 2 BIAS, RMSE and Wilmott index (IC) values for PTL2 and PTL1 positions

\begin{tabular}{llccc}
\hline Sensor positions & Models & BIAS (m) & RMSE (m) & IC (\%) \\
\hline PTL2 & COULWAVE & 0.031 & 0.042 & 98 \\
& 1DL & 0.055 & 0.071 & 88 \\
PTL1 & COULWAVE & 0.024 & 0.045 & 98 \\
& 1DL & -0.026 & 0.054 & 96 \\
\hline
\end{tabular}

where $x_{i}$ are the experimental values and $y_{i}$ are the numerical ones, $x$ is the average of the experimental values and $n$ are the number of points.

For PTL2 sensor position:

- In general, the numerical values show small differences (less then $0.01 \mathrm{~m}$ ) in behaviour and magnitude when compared to the observed ones in the pressure sensors, for the analysed period (with enough water column depth to allow breaking conditions). Moreover, both results show that the values do not change significantly from offshore to inshore, although there is a little increase due to shoaling;

- There are, however, differences between the numerical and measured values. In general, the measured values are lower than the numerical models result, especially between 0:00 and 3:00 am for both models and between 01:00 and 07:00 pm for 1DL results. In fact, between 01:00 to 03:00 pm, 1DL results show the higher differences to the measurements. It must be noticed that this model only takes into account shoaling and refraction and a very simple wave breaking model is included. Therefore, in very shallow waters the behaviour of the model is worse.

- The agreement with measurements is better for COULWAVE model. For this model, the measure of the similarity between the values is given by the Wilmott index, which is $98 \%$ while for 1DL model is only $88 \%$. Also the average of the differences between numerical and experimental values is approximately $0.03 \mathrm{~m}$ for COULWAVE and $0.055 \mathrm{~m}$ for 1DL.

For PTL1 sensor position, in general, the measured and numerical results are similar, for the analysed period (with enough water column depth to allow breaking conditions). Moreover, comparing with the PLT2 sensor position, this agreement is better. Both IC values for COULWAVE and 1DL models are higher than the corresponding ones of PTL2 position. However, there are still differences which can be due to the fact that this sensor is located in a transitional position between the breaking and the swash zone and so several waves do not reach the position sensor.

From the above, one can consider that both models are able to simulate the measured conditions, for both positions. 


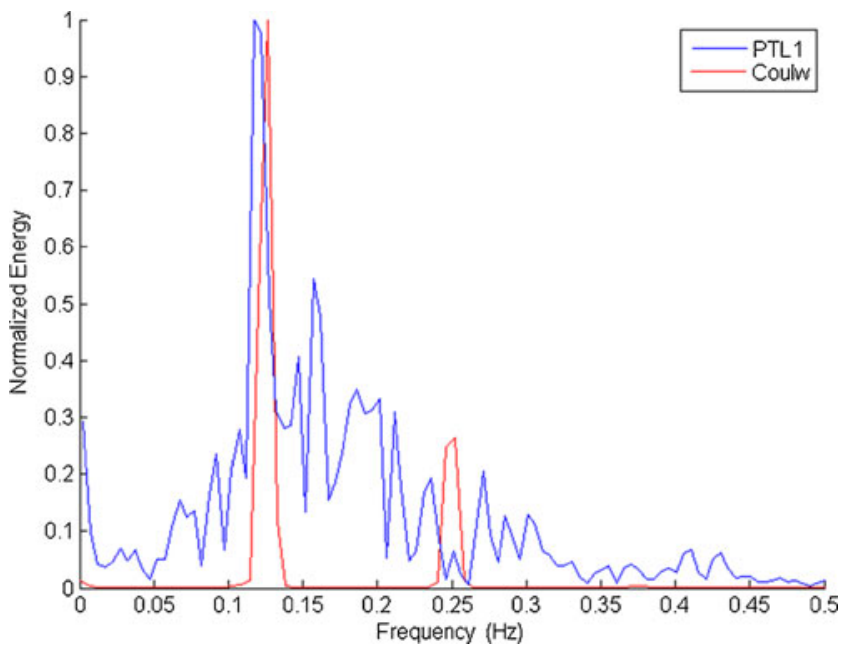

Fig. 13 Field and numerical data spectra for pressure sensor position PTL1 at 27th March (04:10 pm). Numerical results were obtained by using a regular incident wave into COULWAVE model

Anyway with COULWAVE model, it is achieved a better agreement with measurements, but still some differences occurred. Differences between predicted and numerically generated spectra at breaking (PTL1) are significant since natural spectra is very irregular and includes a broad range of periods while the numerical one is based on offshore monochromatic waves, Fig. 13.

Irregular waves Trying to overcome the limitations expressed at the previous item, simulations with the numerical model COULWAVE were performed imposing at the boundary domain the 10 minutes variable free surface elevation obtained at the Infinity PT position at 2:30 am of 27th March. The simulation was carried out for a $1 \mathrm{D}$ situation along the bottom profile $\mathrm{x}=85 \mathrm{~m}$ which include the pressure

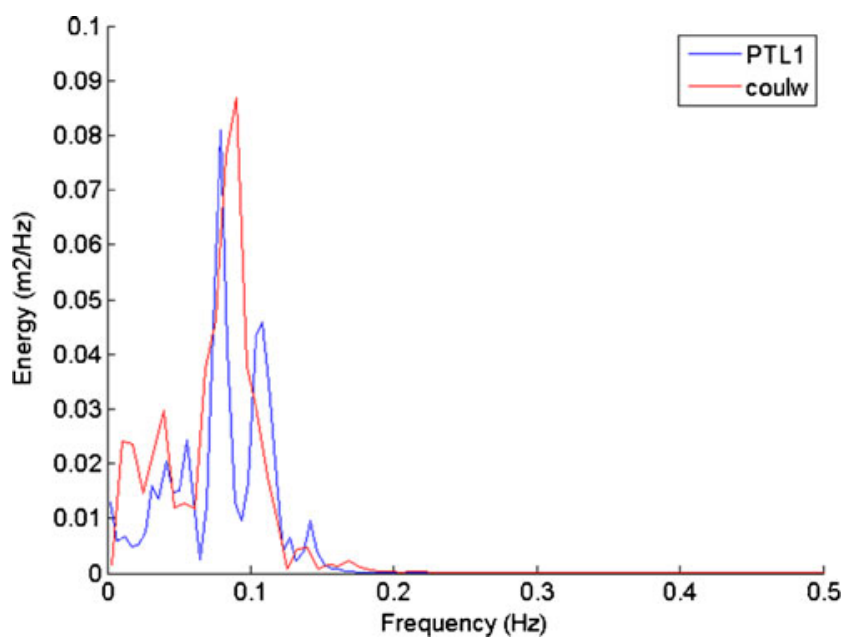

Fig. 14 Field and numerical data spectra for pressure sensor position PTL1 at 2:30 am of 27th March. Numerical results were obtained by using an irregular incident wave into COULWAVE model

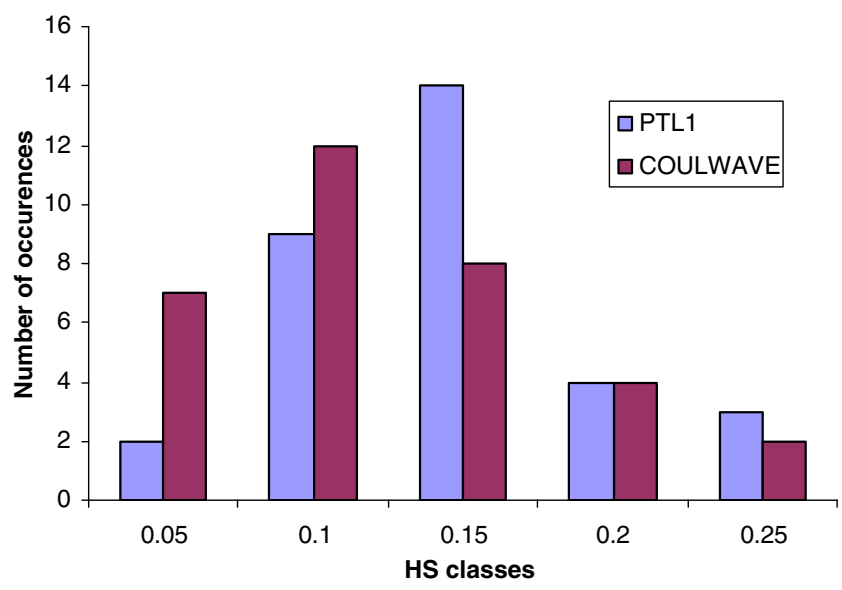

Fig. 15 27th March (2:30 am). Comparison between wave heights histograms for measured (PTL1) and simulated (COULWAVE) conditions. Values in $\mathrm{x}$-axis are central points of each class

sensor PTL1 (Fig. 8a). The numerical parameters were the same as the ones used for the 2D simulation.

Figure 14 presents the energy spectrum of the measured and numerical results while Fig. 15 presents the histograms of the significant wave height.

In terms of the spectra, a reasonable agreement is obtained between the numerical results and field data. The numerical spectra present almost the same peak frequency of that obtained from the field values and their shapes are quite similar (Fig. 14). For the wave heights, Fig. 15, the measured and numerical histograms are similar also, in almost of the wave classes. So, in general, the comparison between the simulated and the collected data shows that this approach can generate a better representation of the local wave climate.

Although of these promising results, there are some differences between the numerical and measured time series of the free surface elevation, as shown in the Fig. 16. Moreover, the root mean squared was $0.05 \mathrm{~m}$ (for all waves generally below $0.30 \mathrm{~m}$ ) and so, the improvement of this method is foreseen.

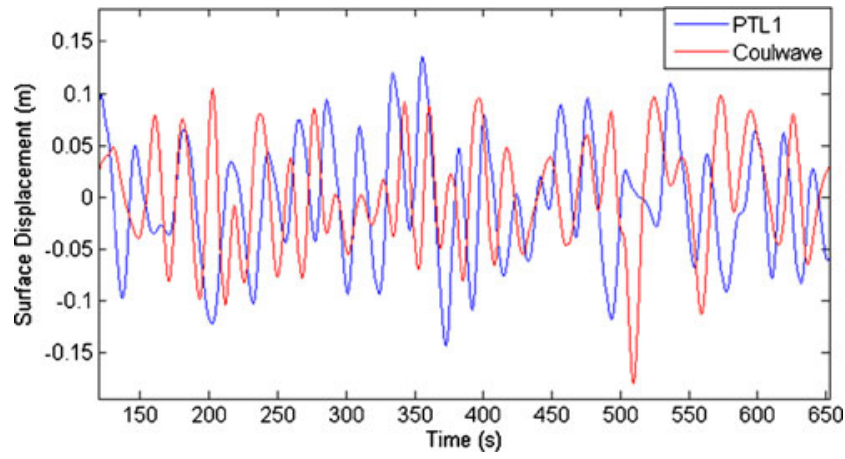

Fig. 16 27th March (2:30 am). Comparison between measured (PTL1) and simulated (COULWAVE) free surface elevation 


\section{Conclusions}

This paper describes the work performed under the project BRISA, namely the wave data collection campaign carried out at the Praia de Faro from the 25th to 28th March 2009, the data analysis performed and finally the numerical simulations of wave propagation for the day of 27th March. These numerical simulations were carried out with two numerical models (1DL and COULWAVE).

Firstly, a regular wave with statistical parameters (HS and TS) similar to the ones observed at the offshore pressure sensor (11.7 $\mathrm{m}$ water depth below MSL) was imposed as boundary conditions, for both models. The comparison between numerical and measured results, in terms of significant wave heights at the pressure sensor PLT2 and PTL1 was performed for this wave condition.

Secondly, for the COULWAVE model, a 10 min-duration time series of free surface elevation was imposed as boundary conditions and a comparison between numerical and measured results, in terms of energy spectra, significant wave heights and the time series of the free surface elevation at the pressure sensor PTL1 was also performed.

The data analysis showed that during the campaign the monitored conditions were rather mild ( $\mathrm{HS}<1 \mathrm{~m}$ ) without significant difference between offshore (at $-11.7 \mathrm{~m}$ water depth) and inshore (at $3.1 \mathrm{~m}$ water depth) conditions, although the inshore values were a little higher than offshore ones due to shoaling. The same does not happen for TS were a small increase was found at the beachface, probably related with wave breaking before reaching the transducer and also to wave/backwash interaction.

Concerning the numerical simulations, the general trend of the significant wave height estimated using both models (1DL and COULWAVE) is similar to those measured in-situ, for pressure sensor positions PLT2 and PTL1. Moreover, the agreement with measurements is better for COULWAVE model. However, differences between observations and predictions still exist, especially for the 1DL model, since this is a simple linear shoaling/refraction model with a simple wave breaking condition. Moreover, due to the lack of information, the wave direction was not considered in the numerical simulations and a regular wave was considered as offshore boundary condition, both of which do not fully represent what happened in the field.

The use of the time series of the free surface elevation as boundary condition for the COULWAVE model is promissory since the comparison between numerical and measured spectra as well as the wave height histograms showed a reasonable agreement between the corresponding values. However, these conclusions were made upon a 10 minutes analysis. A future work will consider simulations for all offshore time series of free surface elevation and the corresponding wave directions. Further comparisons with data from other instruments used in the campaign will be tackled also.
These efforts aim to reach the best possible approach for applications in larger time and spatial scales, required from an operational/management perspective.

Acknowledgments This study is funded by the Science and Technology Foundation of the Ministry of Science, Technology and Higher Education, Portugal under the contracts of SFRH/BPD/20508/2004, PTDC/ECM/67411/2006 and PTDC/ECM/73145/2006.

Open Access This article is distributed under the terms of the Creative Commons Attribution License which permits any use, distribution, and reproduction in any medium, provided the original author(s) and the source are credited.

\section{References}

Carvalho MM (1981) Simulação da Agitação Irregular-Técnicas Matemáticas. Tese para Especialista, LNEC, Lisboa (in Portuguese)

Costa C (1994) Final report of sub-project wind wave climatology of the Portuguese Coast. Report PO-WAVES 6/94-A, IH/LNEC

Costa M, Silva R, Vitorino J (2001) Contribuição para o estudo do clima de agitação marítima na costa portuguesa. 2as Jornadas Portuguesas de Engenharia Costeira e Portuária. Associação Internacional de Navegação. Sines. CD-ROM, 20 pp (in Portuguese)

Damgaard JS, Van Rijn LC, Hall LJ, Soulsby RL (2001) Intercomparison of engineering methods for sand transport. In: van Rijn LC, Davies AG, van de Graaff J, Ribberink JS (eds) SEDMOC-Sediment transport modelling in marine coastal environments. Aqua Publications, The Netherlands, ISBN 90-800356-4-5, pp. CJ 1-12

Dean RG, Dalrymple RA (1991) Water wave mechanics for engineers and scientists, World Scientific

Ferreira L, Antunes P, Domingues F, Fortes CJEM, Silva PA, Nogueira R, Pinto JL, André P (2009) Monitorization of sea sand transport in coastal areas using optical fiber sensors. In: IEEE Sensors Conference 2009, Christchurch, New Zealand, pp. 146-150, 25-28 October 2009, IEEE Computer Society Press. ISBN: 978-1-4244-5335-1

Fortes CJEM, Capitão R (2009) Programas PRE-REGISTOS e REGISTOS. Relatório 01/2009. LNEC (in Portuguese)

Instituto Hidrográfico (1998) Tabela de Marés, volume 1. Lisboa, ed. Instituto Hidrográfico, $178 \mathrm{pp}$ (in Portuguese)

Kennedy AB, Chen Q, Kirby JT, Dalrymple RA (2000) Boussinesq modeling of wave transformation, breaking, and runup. Part I: 1D. J Waterw, Port, Coast Ocean Eng 126(1):39-47

Lynett P, Liu PLF (2004) Modelling wave generation, evolution and interaction with depth-integrated, dispersive wave equations. COULWAVE Code Manual. Cornell Univ. Long Inter. Wave Modelling Package

Matias A, Ferreira Ó, Vila-Concejo A, Garcia T, Dias JA (2008) Classification of washover dynamics in barrier islands. Geomorphology 97(3-4):655-674

Matias A, Vila-Concejo A, Ferreira Ó, Morris B, Dias JA (2009) Sediment dynamics of barriers with frequent overwash. J Coast Res 25(3):768-780

Melo JS (1989) Caracterização Hidro-Oceanográfica da Ria Formosa. Anais do Instituto Hidrográfico (10):7-23 (in Portuguese)

Pessanha LE, Pires HO (1981) Elementos sobre o clima de agitação marítima na costa sul do Algarve, Instituto Nacional de Meteorologia e Geofísica (in Portuguese)

Pires HO (1998) Preliminary report on the wave climate at Faro-Project INDIA. Instituto de Meteorologia - Instituto Superior Técnico, pp. 37

Vila-Concejo A, Matias A, Pacheco A, Ferreira Ó, Dias JA (2006) Quantification of inlet-related hazards in barrier island systems. An example from the Ria Formosa (Portugal). Continent Shelf Res 26(9):1045-1060 